\title{
Stable isotope fractionation during ultraviolet photolysis of $\mathbf{N}_{2} \mathrm{O}$
}

\author{
Thom Rahn ${ }^{1}$, Hui Zhang ${ }^{2}$, Martin Wahlen ${ }^{1}$, and Geoffrey A. Blake ${ }^{2}$
}

\begin{abstract}
The biogeochemical cycling of nitrous oxide plays an important role in greenhouse forcing and ozone regulation. Laboratory studies of $\mathrm{N}_{2} \mathrm{O}: \mathrm{N}_{2}$ mixtures irradiated between 193-207 nm reveal a significant enrichment of the residual heavy nitrous oxide isotopomers. The isotopic signatures resulting from photolysis are well modeled by an irreversible Rayleigh distillation process, with large enrichment factors of $\varepsilon_{15.18}(193 \mathrm{~nm})=-18.4,-14.5$ per mil and $\varepsilon_{15,18}(207 \mathrm{~nm})=-48.7$, 46.0 per mil. These results, when combined with diffusive mixing processes, have the potential to explain the stratospheric enrichments previously observed.
\end{abstract}

\section{Introduction}

Nitrous oxide is a trace gas that is produced during microbial energy exchange reactions involving both reduced $\left(\mathrm{NH}_{3}\right)$ and oxidized $\left(\mathrm{NO}_{3}{ }^{-}\right)$forms of nitrogen, processes which are widespread in soils and in the world's oceans. A portion of the $\mathrm{N}_{2} \mathrm{O}$ that is produced escapes to the troposphere where it is chemically inert and eventually ascends to the stratosphere where it is photolyzed by ultraviolet radiation, oxidized by excited atomic oxygen, or returned to the troposphere during stratosphere/troposphere exchange processes. While in the atmosphere, $\mathrm{N}_{2} \mathrm{O}$ actively absorbs infrared radiation and thereby contributes to greenhouse warming. A portion of the $\mathrm{N}_{2} \mathrm{O}$ destroyed by reaction with $O\left({ }^{1} D\right)$ provides the principle natural source of NO, which initiates the catalytic $\mathrm{NO}_{x}$ cycling of stratospheric ozone. The current tropospheric concentration is about $313 \mathrm{ppbv}$ [R. Weiss, pers. comm.] and is increasing at a rate of $\sim 0.25 \%$ per year.

Efforts to determine the global budget of $\mathrm{N}_{2} \mathrm{O}$ have included investigations of the stable isotopic signatures of the various sources and sinks [Moore, 1974; Yoshida and Matsuo, 1983; Wahlen and Yoshinari, 1985; Yoshinari and Wahlen, 1985; Kim and Craig, 1990; Kim and Craig, 1993; Yoshinari, et al., 1997; Cliff and Thiemens, 1997; Rahn and Wahlen, 1997; Naqvi, et al., 1998]. Two of these studies [Moore, 1974; Kim and Craig, 1993] showed that $\mathrm{N}_{2} \mathrm{O}$ collected from the lower stratosphere was substantially enriched in ${ }^{15} \mathrm{~N}$ and ${ }^{18} \mathrm{O}$, but only three samples were isotopically analyzed. We expanded this lower stratosphere database with seven additional samples which revealed a coherent trend with concentration that was consistent with a single stage Rayleigh distillation model [Rahn and Wahlen, 1997] (RW97).

Rayleigh distillation describes an irreversible sink with the resulting isotopic enrichment related to the fraction remaining by the expression

\footnotetext{
${ }^{1}$ Scripps Institution of Oceanography, University of California, San Diego, La Jolla, CA 92093-0220, USA.

Division of Geological \& Planetary Sciences, California Institute of Technology, Mail Stop 150-21, Pasadena, CA 91125 , USA.
}

Copyright 1998 by the American Geophysical Union.

$$
R=R_{0} f^{(\alpha-1)}
$$

where $R$ and $R_{o}$ are the residual and initial heavy-to-light isotope ratios, $f$ is the fraction of $\mathrm{N}_{2} \mathrm{O}$ remaining (i.e. the stratospheric concentration divided by the tropospheric concentration), and $\alpha$ is the ratio of the heavy-to-light reaction or photolysis rates. This relationship can be approximated by $\delta \cong \delta_{0}+\varepsilon \times \ln (f)$, where the slope, $\varepsilon=1000(\alpha-1)$, is the enrichment factor expressed in per mil. The $\delta$ and $\delta_{0}$ terms, also expressed in per mil, are the residual and initial delta values, with $\delta_{i}=\left(R_{i} / R_{s t d}-1\right) * 1000$, where $\mathbf{R}_{\mathbf{i}}$ and $\mathbf{R}_{\text {std }}$ are the heavy-to-light isotopic ratios in the sample and in the standard. The enrichment factors determined from the stratospheric samples were $\varepsilon=-\mathbf{1 4 . 5}$ per mil and -12.9 per mil for ${ }^{15} \mathrm{~N}$ and ${ }^{18} \mathrm{O}$, respectively.

The isotopic enrichments observed in the stratosphere have lead to speculation about the validity of the currently accepted conceptual model of $\mathrm{N}_{2} \mathrm{O}$ stratospheric chemistry. Standard theory holds that $90 \%$ of the $\mathrm{N}_{2} \mathrm{O}$ loss in the stratosphere occurs via the photolytic reaction

$$
\mathrm{N}_{2} \mathrm{O}+\mathrm{hv} \rightarrow \mathrm{N}_{2}+\mathrm{O}\left({ }^{1} \mathrm{D}\right) \quad(\lambda \cong 180-215 \mathrm{~nm}),
$$

that $10 \%$ is lost via the two branches of the reaction with excited atomic oxygen;

$$
\begin{aligned}
& \mathrm{N}_{2} \mathrm{O}+\mathrm{O}\left({ }^{1} \mathrm{D}\right) \rightarrow \mathrm{NO}+\mathrm{NO} \\
& \mathrm{N}_{2} \mathrm{O}+\mathrm{O}\left({ }^{1} \mathrm{D}\right) \rightarrow \mathrm{N}_{2}+\mathrm{O}_{2}
\end{aligned}
$$

and that there are no significant atmospheric sources of $\mathrm{N}_{2} \mathrm{O}$. Experiments by Johnston et al. [1995] (JCT95) found negligible ${ }^{18} \mathrm{O}$ fractionation during reaction $\mathrm{R} 1$ and a $\varepsilon_{18}=-6$ per mil enrichment for the photo-oxidation reactions $\mathrm{R} 2 \mathrm{a}$ and $\mathrm{R} 2 \mathrm{~b}$. This led a number of researchers to propose a variety of source reactions with ostensibly large enrichment factors to explain the observed enrichment [McElroy and Jones, 1996; Prasad, 1997; Prasad, et al., 1997]. On the other hand, the more recent data of RW97 are compatible with a single stage loss process, indicating that the mechanism responsible for the observed enrichment is most likely a sink.

An explanation for the apparent incompatibility of observations and laboratory results has been proposed by Yung and Miller [1997] (YM97). The photolysis experiments of JCT95 were performed with a $\mathrm{Hg}$ arc lamp at $184.9 \mathrm{~nm}$, near the peak of the $\mathrm{N}_{2} \mathrm{O}$ absorption continuum. Citing the small shifts in the $\mathrm{N}_{2} \mathrm{O}$ UV cross sections with isotopic substitution observed by Selwyn and Johnston [1981], JCT95 concluded that fractionation should be inconsequential when averaged across the continuum. However, as pointed out by Froidevaux and Yung [1982] and Minschwaner et al. [1993], while the $\mathrm{N}_{2} \mathrm{O}$ cross section does indeed peak at $-182 \mathrm{~nm}$, the photolysis in the stratosphere occurs principally at longer wavelengths, specifically in the $190-210 \mathrm{~nm}$ window defined by the $\mathrm{O}_{2}$ Schumann-Runge bands to the blue and $\mathrm{O}_{2}$ Herzberg continuum plus ozone Hartley and Huggins band absorption to the red.

Mindful of this, YM97 proposed a wavelength-dependent mechanism for the photolytic fractionation of $\mathrm{N}_{2} \mathrm{O}$ based on subtle 
shifts in the zero point energy with isotopic substitution. While the cross sections are essentially identical at the absorption peak, a clear separation is manifest on both shoulders. Analogous to determining the kinetic fractionation for a chemical reaction, the photolysis fractionation factor will be equal to the ratio of the heavy-to-light photolysis rates and thus to the ratio of the cross sections. For $\mathrm{N}_{2} \mathrm{O}$, the theoretical enrichment factors can be calculated analytically as a function of wavelength using the spectral function recommended by Selwyn et al. [1977]. At wavelengths shorter than $\sim 182 \mathrm{~nm}, \varepsilon$ is initially positive, but passes through zero at the cross section maximum and gets progressively more negative with increasing wavelength.

We have performed a series of photolysis experiments at 193 and $207 \mathrm{~nm}$ followed by mass spectrometry to investigate the validity of the YM97 theory. While we do indeed observe significant enrichment of the heavy isotopic species in the residual $\mathrm{N}_{2} \mathrm{O}$, the magnitude of the enrichment is approximately double that predicted.

\section{Experimental and Results}

Aliquots of our isotopic standard nitrous oxide working-gas (SNOW) were introduced to a jacketed glass cell of $4 \mathrm{~cm}$ inside diameter and $25 \mathrm{~cm}$ length (approximately $300 \mathrm{~cm}^{3}$ volume) fitted with ports for sample inlet and vacuum lines. The cell was equipped with UV-transparent fused silica windows of half inch diameter and $2 \mathrm{~mm}$ thickness, with an optically illuminated area estimated at $0.8 \mathrm{~cm}^{2}$. The jacketed outer layer was equipped with ports for fluid circulation to facilitate temperature control. Tunable UV radiation between $205-225 \mathrm{~nm}$ was generated by a frequency doubled type II beta-barium borate ( $\beta-\mathrm{BaB}_{2} \mathrm{O}_{4}$ or $\mathrm{BBO}$ ) optical parametric oscillator (OPO) pumped by the third harmonic

Table 1. Isotopic Signatures of $\mathrm{N}_{2} \mathrm{O}$ Following Varying Degrees of Photolysis at 207 and $193 \mathrm{~nm}$.

\begin{tabular}{|c|c|c|c|c|c|c|}
\hline Samp & $\begin{array}{c}\lambda \\
\mathrm{nm}\end{array}$ & $\begin{array}{l}\text { Residual } \\
\text { Fraction }\end{array}$ & $\ln (f)$ & $\begin{array}{c}\delta^{15} \mathrm{~N} \\
\text { per mil }\end{array}$ & $\begin{array}{c}\delta^{18} \mathrm{O} \\
\text { per mil }\end{array}$ & notes' \\
\hline 24 & 207.6 & 0.88 & -0.13 & 5.4 & 5.3 & see text \\
\hline 26 & 207.8 & 0.81 & -0.21 & 9.9 & 9.4 & see text \\
\hline 27 & 207.8 & 0.76 & -0.27 & 12.5 & 11.9 & see text \\
\hline 29 & 207.4 & 0.72 & -0.33 & 16.0 & 15.0 & see text \\
\hline 32 & - & 1.00 & 0.00 & -0.1 & -0.2 & np \\
\hline 34 & 207.4 & 0.85 & -0.16 & 7.3 & 6.9 & $300: 1 \mathrm{~N}_{2}: \mathrm{N}_{2} \mathrm{O}$ \\
\hline 49 & 193.0 & 0.85 & -0.17 & 3.5 & 2.7 & $3 \mathrm{~min}, 100 \mathrm{~Hz}, 3.1 \mathrm{~mJ}$ \\
\hline 50 & 193.0 & 0.61 & -0.50 & 10.4 & 7.9 & $6 \mathrm{~min}, 100 \mathrm{~Hz}, 3.8 \mathrm{~mJ}$ \\
\hline 51 & 193.0 & 0.79 & -0.24 & 5.2 & 4.0 & $3 \mathrm{~min}, 100 \mathrm{~Hz}, 3.8 \mathrm{~mJ}$ \\
\hline 52 & 193.0 & 0.75 & -0.29 & 6.1 & 4.7 & $1.5 \mathrm{mun}, 100 \mathrm{~Hz}, 8.0 \mathrm{~mJ}$ \\
\hline 53 & 193.0 & 0.59 & -0.53 & 10.8 & 8.3 & $3 \mathrm{~min}, 100 \mathrm{~Hz}, 8.0 \mathrm{~mJ}$ \\
\hline 54 & 193.0 & 0.43 & -0.83 & 15.7 & 12.2 & $5 \mathrm{~min}, 100 \mathrm{~Hz}, 8.0 \mathrm{~mJ}$ \\
\hline 56 & - & 1.00 & 0.00 & -0.2 & -0.4 & np \\
\hline 57 & 193.0 & 0.43 & -0.84 & 15.3 & 12.0 & $5 \mathrm{~min}, 100 \mathrm{~Hz}, 8.4 \mathrm{~mJ}$ \\
\hline 58 & 193.0 & 0.44 & -0.81 & 15.3 & 11.9 & $5 \mathrm{~min}, 100 \mathrm{~Hz}, 8.4 \mathrm{~mJ}$ \\
\hline 59 & 193.0 & 0.82 & -0.20 & 4.4 & 3.2 & $60 \mathrm{~min}, 10 \mathrm{~Hz}, 1.5 \mathrm{~mJ}$ \\
\hline 61 & 193.0 & 0.83 & -0.19 & 3.9 & 2.7 & $12 \mathrm{~min}, 10 \mathrm{~Hz}, 4.5 \mathrm{~mJ}$ \\
\hline 62 & 193.0 & 0.83 & -0.18 & 3.9 & 2.8 & $1.2 \mathrm{~min}, 100 \mathrm{~Hz}, 7.0 \mathrm{~mJ}$ \\
\hline 63 & 193.0 & 0.79 & -0.24 & 5.1 & 3.8 & $120 \mathrm{~min}, 1 \mathrm{~Hz}, 6.2 \mathrm{~mJ}$ \\
\hline 40 & - & 1.00 & 0.00 & 0.2 & 0.6 & np \\
\hline 45 & - & 1.00 & 0.00 & 0.1 & 0.1 & np \\
\hline 46 & - & 1.00 & 0.00 & 0.1 & 0.2 & np \\
\hline
\end{tabular}

${ }^{1}$ Replicate analyses of samples processed with no irradiation (indicated with $\mathrm{np}=$ no photolysis) indicate a precision of \pm 0.2 and \pm 0.4 for $\delta^{15} \mathrm{~N}$ and $\delta^{18} \mathrm{O}$, respectively, for the combined extraction procedure and mass spectrometric analysis. The extraction procedures allow for a $\ln (f)$ precision of \pm 3 percent as determined from the yield of the np samples. Isotopic results are reported relative to our standard $\mathrm{N}_{2} \mathrm{O}$ working-gas (SNOW). Unless otherwise noted, $\mathrm{N}_{2}: \mathrm{N}_{2} \mathrm{O}$ ratios are 150:1.

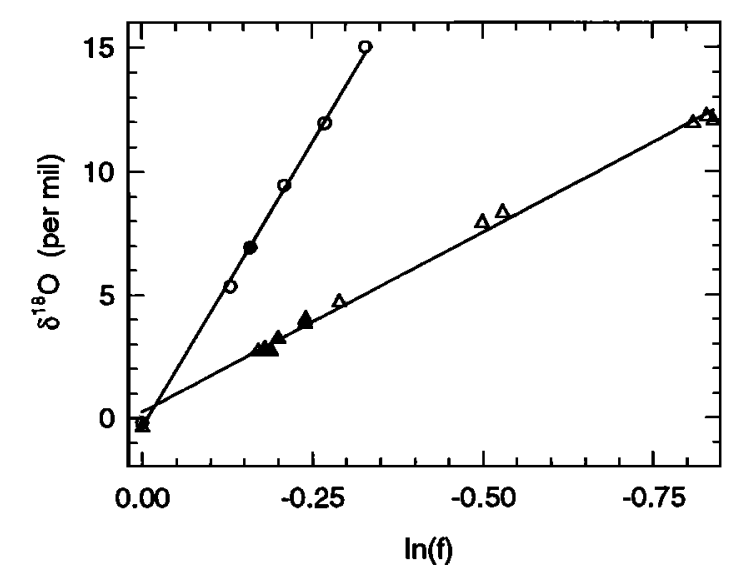

Figure 1. Rayleigh distillation plot of the enrichment of $\mathrm{N}_{2}{ }^{18} \mathrm{O}$ during photolysis at 207 and $193 \mathrm{~nm}$. Open circles record the room temperature data at $207 \mathrm{~nm}$ for samples with an $\mathrm{N}_{2}$ quenching ratio of 150:1. Falling almost directly on the $207 \mathrm{~nm}$ fitted line is the filled circle, representative of the sample in which the quenching ratio was increased to 300:1. Open triangles record the room temperature data at $193 \mathrm{~nm}$ with an $\mathrm{N}_{2}$ quenching ratio of 150:1 and constant pulse frequency, while the filled triangles indicate samples in which the peak power and pulse frequency were varied to test for multi-photon effects and for secondary production of $\mathrm{N}_{2} \mathrm{O}$. The lines are least squares fits to the open symbol data and yield enrichment factors of $\varepsilon_{18}(207 \mathrm{~nm})$ $=-46.0$ per mil (samples $24-32)$ and $\varepsilon_{18}(193 \mathrm{~nm})=-14.5$ per mil (samples 49-58). Errors are as described in Table 1. A similar plot for ${ }^{15} \mathrm{~N}$ can be generated from the data in Table 1 .

of a Coherent Infinity Nd:YAG laser. The OPO has been described in detail elsewhere [Wu, et al., 1997]. The light source operates at repetition rates up to $100 \mathrm{~Hz}$ with a $205-220 \mathrm{~nm}$ pulse energy of $\sim 1-2 \mathrm{~mJ}$, a line width of $-1.5-2.5 \mathrm{~cm}^{-1}$, and a pulse duration of $\sim 2$ ns. At $193 \mathrm{~nm}$, the output of a Lambda Physik LPX 120i excimer laser was used, which has a somewhat longer pulse duration of $\sim 17-20 \mathrm{~ns}$ and a line width of $\sim 400 \mathrm{~cm}^{-1}$. Pulse energies are recorded in Table 1 and are estimated to be stable within $\pm 1 \mathrm{~mJ}$ over the course of a run. To test for the presence of multi-photon effects, the peak power was varied by factors of $>3$ 5 , and no statistically significant trends were seen. Samples were irradiated for different time periods ranging from a few minutes to several hours.

In order to suppress reaction of the $\mathrm{N}_{2} \mathrm{O}$ sample with $\mathrm{O}\left({ }^{1} \mathrm{D}\right)$ formed during photolysis, ultra-high purity $\mathrm{N}_{2}$ gas was added as a quenching agent, typically at a $\mathrm{N}_{2}: \mathrm{N}_{2} \mathrm{O}$ ratio of $150: 1$. The rate constant for the reaction of $\mathrm{O}\left({ }^{1} D\right)$ and $\mathrm{N}_{2}$ to form $\mathrm{N}_{2} \mathrm{O}$ has been shown to be extremely slow due to an electronic curve crossing [DeMore, et al., 1996]. Production of $\mathrm{N}_{2} \mathrm{O}$ via heterogeneous reactions involving $\mathrm{N}_{2}$ and atomic oxygen are also expected to be negligible relative to the sample size [Maric and Burrows, 1992; JCT95]. Varying amounts of $\mathrm{N}_{2}$ were added to examine the quenching efficiency, and several samples were processed without irradiation in order to verify the gas handling procedures. After each run, samples were bled to a vacuum extraction line where the residual $\mathrm{N}_{2} \mathrm{O}$ was trapped cryogenically, tested for photolysis extent by manometry, and collected in flame sealed $6 \mathrm{~mm}$ glass tubes for subsequent isotopic analysis on a VG-Prism II mass spectrometer. The methodology for the direct injection of $\mathrm{N}_{2} \mathrm{O}$ into the VG triple collector mass spectrometer has been described in RW97 and includes monitoring of peaks at M/z=12 and 22 for possible $\mathrm{CO}_{2}$ contamination. 
The results of the experimental analyses are recorded in Table 1 and shown graphically in Fig. 1. The data are clearly consistent with a simple Rayleigh fractionation model, and the trend of the heavy isotope enrichment with wavelength is consistent with that predicted by YM97. For example, the ${ }^{18} \mathrm{O}$ enrichments at 193.0 and $207.6 \mathrm{~nm}$ are found to be $\varepsilon_{18}(193 \mathrm{~nm})=-14.5$ per mil and $\varepsilon_{18}(207 \mathrm{~nm})=-46.0$ per mil. Doubling the quenching ratio (sample \# 34), varying the laser power (sample \#'s 49, 51, 53), or varying the laser power and pulse frequency/irradiation period (sample \#'s 59, 61, 62, 63), had no additional effect on the isotopic signature. These results virtually rule out any significant production of $\mathrm{N}_{2} \mathrm{O}$ by reaction with atomic oxygen, in either third body or heterogeneous reactions, as any production would be expected to have a dependence both on the reactant concentrations and on reaction rates. Therefore, the observed fractionation should be that due to photolysis alone. Interestingly, the enrichment factors measured here are more than twice that predicted by YM97, for which $\varepsilon_{18}(Y M 97)=-9.1$ and -21.3 per mil at 193.0 and $207.6 \mathrm{~nm}$, respectively.

The same general observations made for the ${ }^{18} \mathrm{O}$ data apply to the ${ }^{15} \mathrm{~N}$ data sets with the following caveat. The analyses of the ${ }^{15} \mathrm{~N}$ data are complicated by the fact that there are three additional isotopomers to be accounted for, ${ }^{14} \mathrm{~N}^{15} \mathrm{NO},{ }^{15} \mathrm{~N}^{14} \mathrm{NO}$, and ${ }^{14} \mathrm{~N}^{14} \mathrm{~N}^{17} \mathrm{O}$. The first two of these are not distinguishable with current mass spectrometric analytical methods, and YM97 accounted for this complexity by averaging the enrichment of the two ${ }^{15} \mathrm{~N}$ species. We have accounted for the ${ }^{14} \mathrm{~N}^{14} \mathrm{~N}^{17} \mathrm{O}$ isotopomer in our experimental data by applying a variation of the standard correction [Craig, 1957] which assumes mass dependent enrichment. The theoretical enrichment factors are $\varepsilon_{15}$ (YM97) $=$ -10.4 and -24.0 per mil at 193.0 and $207.6 \mathrm{~nm}$. The values obtained from the experimental data are $\varepsilon_{15}(193 \mathrm{~nm})=-18.4$ per mil and $\varepsilon_{15}(207 \mathrm{~nm})=-48.7$ per mil, again roughly double that predicted by the model. Correcting for ${ }^{17} \mathrm{O}$ by assuming mass dependent enrichment is considered valid since any mass independent enrichment on the order of that observed by Cliff and Thiemens [1997] would result in additional corrections which are smaller than the experimental precision reported in Table 1 [see for instance Röckmann and Brenninkmeijer, 1998].

\section{Atmospheric Implications}

The results of this study verify that $\mathrm{UV}$ photolysis of $\mathrm{N}_{2} \mathrm{O}$ at the investigated wavelengths yields significant isotopic enrichment in the residual gas. Furthermore, we observe that a comparison of the enrichments of ${ }^{15} \mathrm{~N}$ to ${ }^{18} \mathrm{O}$ yields ratios of slightly greater than unity. This is nearly identical to the ratio of the enrichments observed in RW97 and close to that predicted by YM97, and supports the hypothesis that photolysis is the mechanism responsible for the observed stratospheric enrichments and that the standard model of stratospheric $\mathrm{N}_{2} \mathrm{O}$ chemistry is essentially complete. While the absolute magnitude of the fractionation observed in the laboratory is significantly different from that predicted by YM97, the general concept of enrichment being caused by a spectral shift with isotopic substitution is still a valid and likely mechanism. A more rigorous treatment of the zero point energy shifts proposed by YM97, including non-Born-Oppenheimer effects and dipole moment surface variations, might yield better quantitative agreement.

The absolute magnitude of the laboratory enrichments are also problematic when compared to the enrichments observed by RW97 in the stratosphere. To determine how stratospheric mixing processes might influence the observed isotopic enrichment factors for a tracer which has a decay constant $\lambda_{\mathrm{A}}$ and no in situ production, we consider the one-dimensional (1D) diffusionlimited case where the steady state continuity equation for trace species $A$ is reduced to

$$
\mathrm{K}_{\mathrm{D}} \frac{\partial^{2}[\mathrm{~A}]}{\partial \mathrm{z}^{2}}-\lambda_{\mathrm{A}} \frac{\partial[\mathrm{A}]}{\partial \mathrm{z}}=0
$$

$K_{D}$ being the eddy diffusion coefficient and $z$ being the height above the tropopause. With the boundary conditions $A=A_{0}$ at $\mathrm{z}(0)$ and $\mathrm{A}=0$ at $\mathrm{z}(\infty)$, Eq. 2 has the solution

$$
A=A_{0} \exp \left(-z \sqrt{\frac{\lambda_{A}}{K_{D}}}\right)
$$

If $B$ is the isotopically substituted species, then $R=\frac{B}{A}$ and

$$
\frac{R}{R_{0}}=\exp \left[-\mathrm{z}\left(\frac{\sqrt{\lambda_{\mathrm{B}}}-\sqrt{\lambda_{\mathrm{A}}}}{\sqrt{\mathrm{K}_{\mathrm{D}}}}\right)\right] \text {. }
$$

Recognizing that $f=\frac{A}{A_{0}}$ and $\ln (f)=-z \sqrt{\frac{\lambda_{A}}{K_{D}}}$, Eq. 3 yields

$$
R=R_{0} f\left(\sqrt{\frac{\lambda_{B}}{\lambda_{A}}}-1\right)
$$

which is of the form of Eq. 1. Since $\alpha$ is equal to the ratio of the heavy-to-light reaction rates, it is apparent that the effective fractionation in this $1 \mathrm{D}$ diffusive system is

$$
\alpha_{\text {eff }}=\sqrt{\frac{\lambda_{\mathrm{B}}}{\lambda_{\mathrm{A}}}} \quad \text {, or } \quad \alpha_{\text {eff }}=\sqrt{\alpha} \quad \text {; }
$$

and, since $\alpha=(1+\varepsilon / 1000), \varepsilon_{\text {eff }} \sim \varepsilon / 2$ [see also, Eriksson, 1965]. If we consider the fractionation at $205 \mathrm{~nm}$ to be representative of the integrated stratospheric fractionation (as in YM97) and further assume a linear dependence between the laboratory results at 193 and $207 \mathrm{~nm}$, then the effective enrichment factors are $\varepsilon_{15 e f f}$ $=-21.8$ per mil and $\varepsilon_{18 \text { eff }}=-20.4$ per mil, in much closer agreement with the stratospheric measurements of RW97. A choice of $200 \mathrm{~nm}$ as the representative wavelength brings the effective enrichments into even closer agreement with $\varepsilon_{15 \text { eff }}=$ 16.7 per mil and $\varepsilon_{1 \text { eeff }}=-15.1$ per mil. In either case, the actual fractionation measured in the laboratory $(\alpha)$ far exceeds the observed in situ fractionation as it must in order to account for eddy diffusion in the stratosphere as described above.

In regard to the wavelength chosen to be representative of the integrated stratospheric fractionation, it is important to note that the stratospheric isotopic signature is the result of the midstratosphere radiation field integrated over the range of $\mathrm{N}_{2} \mathrm{O} \mathrm{UV}$ absorption and that the polynomial expression used by YM97 for the cross section spectral dependence is only an approximation. Indeed, a significant amount of vibrational structure is seen in the cross section at wavelengths below $190 \mathrm{~nm}$ [Selwyn and Johnston, 1981] which results in multiple curve crossings with small spectral shifts. Since the YM97 enrichment factors change sign below a cross section maximum, and since there are well defined transmission windows in the Schumann-Runge bands, we postulate that enrichments of opposite sign below $190 \mathrm{~nm}$ may compensate for the large negative $\varepsilon$ 's at longer wavelengths. The ratio of the measured enrichment factors for ${ }^{15} \mathrm{~N}$ and ${ }^{18} \mathrm{O}$ at 193 
$\mathrm{nm}$ is rather different than those measured at $\lambda>207 \mathrm{~nm}$, and may in part be due to the continuation of such vibrational structure, structure that is not accounted for in the spectral function of Selwyn et al. [1977] nor in the YM97 model, yet which is clearly present in the laboratory cross section data [Selwyn and Johnston, 1981; Yoshino, et al., 1984].

The fact that one of the dominant isotopic signatures in atmospheric nitrous oxide arises from UV photolysis not only obviates the need for "exotic" chemistry, it makes this species a powerful tool for addressing important issues in global climate change. For example, it should provide a unique signature to distinguish between fractionation occurring in the upper atmosphere and that resulting from biological or anthropogenic processes, thereby helping in $\mathrm{N}_{2} \mathrm{O}$ budgetary analyses and quantifying stratospheric back-fluxing. Further, because the photolytic isotope fractionation only occurs in the mid- to upperstratosphere, the extent to which the integrated photolytic fractionation exceeds the in situ stratospheric observations may help to determine the degree of mixing between "aged" and "new" stratospheric air. Finally, a better understanding of atmospheric dynamics would enable models to better reproduce the observed distribution of various gases and help to predict the atmospheric response to human activities.

Acknowledgements. We thank A. Spivack and Y. Yung for helpful discussions. Support for the light sources used in this work from the NSF MRI program (grant ATM-9724500 to GAB) is gratefully acknowledged.

\section{References}

Cliff, S. S., and M. H Thiemens, The ${ }^{18} \mathrm{O} /{ }^{16} \mathrm{O}$ and ${ }^{17} \mathrm{O} /{ }^{16} \mathrm{O}$ ratios in atmospheric nitrous oxide: A mass-independent anomaly, Science, 278, 1774-1776, 1997.

Craig, H., Isotopic standards for carbon and oxygen and correction factors for mass-spectrometric analysis of carbon dioxide, Geochim. Cosmochim. Act., 12, 133-149, 1957.

DeMore, W. B., et al., Chemical kinetics and photochemical data for use in stratospheric modeling, evaluation number 11, JPL publication 94-26, Jet Propulsion Laboratory, California Institute of Technology, Pasadena, CA, 1996.

Eriksson, E., Deuterium and oxygen-18 in precipitation and other natural waters: Some theoretical considerations, Tellus, XXVI, 498$512,1965$.

Froidevaux, L., and Y. Yung, Radiation and chemistry in the stratosphere: Sensitivity to $\mathrm{O}_{2}$ absorption cross sections in the Herzberg continuum, Geophys. Res. Lett., 9, 854-857, 1982.

Johnston, J. C., S. Cliff, and M. Thiemens, Measurement of multioxygen isotopic $\left(\delta^{18} \mathrm{O}\right.$ and $\left.\delta^{17} \mathrm{O}\right)$ fractionation factors in the stratospheric sink reactions of nitrous oxide, J. Geophys. Res., 100, $16801-16804,1995$.

Kim, K.-R., and H. Craig, Two isotope characterization of $\mathrm{N}_{2} \mathrm{O}$ in the Pacific Ocean and constraints on its origin in deep water, Nature, $347,58-61,1990$.

Kim, K.-R., and H. Craig, Nitrogen-15 and oxygen-18 characteristics of nitrous oxide: A global perspective, Science, 262, 1855-1857, 1993.

Maric, D., and J. P. Burrows, Formation of $\mathrm{N}_{2} \mathrm{O}$ in the photolysis/photoexcitation of $\mathrm{NO}, \mathrm{NO}_{2}$ and air, J. Photochem. Photobiol. A, 66, 291-312, 1992.
McElroy, M. B., and D. B. A. Jones, Evidence for an additional source of atmospheric $\mathrm{N}_{2} \mathrm{O}$, Glob. Biogeochem. Cycles, 10, 651-659, 1996.

Minschwaner, K., R. J. Salawitch, and M. B. McElroy, Absorption of solar radiation by $\mathrm{O}_{2}$ : Implications for $\mathrm{O}_{3}$ and lifetimes of $\mathrm{N}_{2} \mathrm{O}$, $\mathrm{CFCl}_{3}$, and $\mathrm{CF}_{2} \mathrm{Cl}_{2}$, J. Geophys. Res., 98, 10543-10561, 1993.

Moore, $\mathbf{H}$., Isotopic measurement of atmospheric nitrogen compounds, Tellus, XXVI, 169-174, 1974.

Naqvi, S. W. A., et al., Budgetary and biogeochemical implications of $\mathrm{N}_{2} \mathrm{O}$ isotope signatures in the Arabian Sea, Nature, 394, 462-464, 1998.

Pearman, G. I., et al., Evidence of changing concentrations of atmospheric $\mathrm{CO}_{2}, \mathrm{~N}_{2} \mathrm{O}$ and $\mathrm{CH}_{4}$ from air bubbles in Antarctic ice, Nature, 320, 248-250, 1986.

Prasad, S. S., Potential atmospheric sources and sinks of nitrous oxide 2: Possibilities from excited $\mathrm{O}_{2}$, "embryonic" $\mathrm{O}_{3}$, and optically pumped excited O3, J. Geophys. Res., 102, 21527-21536, 1997.

Prasad, S. S., E. C. Zipf, and X. P. Zhao, Potential atmospheric sources and sinks of nitrous oxide 3: Consistency with the observed distributions of the mixing ratios, J. Geophys. Res., 102, 2153721541, 1997.

Rahn, T., and M. Wahlen, Stable isotope enrichment in stratospheric nitrous oxide, Science, 278, 1776-1778, 1997.

Röckmann, T., and C. A. M. Brenninkmeijer, The error in conventionally reported ${ }^{13} \mathrm{C} /{ }^{12} \mathrm{C}$ ratios of atmospheric $\mathrm{CO}$ due to the presence of mass independent oxygen isotope enrichment, Geophys. Res. Lett., 25, 3163-3166, 1998.

Selwyn, G., J. Podolske, and H. S. Johnston, Nitrous oxide ultraviolet absorption spectrum at stratospheric temperatures, Geophys. Res. Lett., 4, 427-430, 1977.

Selwyn, G., and H. S. Johnston, Ultraviolet absorption spectrum of nitrous oxide as function of temperature and isotopic substitution, $J$. Chem. Phys., 74, 3791-3803, 1981.

Wahlen, M., and T. Yoshinari, Oxygen isotope ratios in $\mathrm{N}_{2} \mathrm{O}$ from different environments, Nature, 313, 780-782, 1985.

Wu, S., G. A. Blake, Z. Y. Sun, and J. W. Ling, Simple, highperformance type II beta- $\mathrm{BaB}_{2} \mathrm{O}_{4}$ optical parametric oscillator, Applied Optics, 36, 5898-5901, 1997.

Yoshida, N., and S. Matsuo, Nitrogen isotope ratio of atmospheric $\mathrm{N}_{2} \mathrm{O}$ as a key to the global cycle of $\mathrm{N}_{2} \mathrm{O}$, Geochemical J., 17, 231-239, 1983.

Yoshinari, T., and $M$. Wahlen, Oxygen isotope ratios in $\mathrm{N}_{2} \mathrm{O}$ from nitrification at a wastewater treatment facility, Nature, 317, 349$350,1985$.

Yoshinari, T., et al., Nitrogen and oxygen isotopic composition of $\mathrm{N}_{2} \mathrm{O}$ from suboxic waters of the eastern tropical North Pacific and the Arabian Sea - measurement by continuous-flow isotope-ratio monitoring, Marine Chem., 56, 253-264, 1997.

Yoshino, K., D. E. Freeman, and W. H. Parkinson, High resolution absorption cross section measurements of $\mathrm{N}_{2} \mathrm{O}$ at $225-299 \mathrm{~K}$ in the wavelength region 170-222 nm, Planetary Space Science, 32, 1219$1222,1984$.

Yung, Y. L., and C. E. Miller, Isotopic fractionation of stratospheric nitrous oxide via photolysis, Science, 278, 1778-1780, 1997.

T. Rahn, M. Wahlen, Scripps Institution of Oceanography, University of California, San Diego, La Jolla, CA 92093-0220, USA. (email: trahn@ucsd.edu; mwahlen@ucsd.edu)

H. Zhang, G. Blake, Division of Geological \& Planetary Sciences, California Institute of Technology, Mail Stop 150-21, Pasadena, CA 91125, USA. (e-mail: hui@gps.caltech.edu; gab@gps.caltech.edu)

(Received August 25, 1998; revised October 14, 1998; accepted October 23, 1998.) 